\title{
The Logical Problem of the Trinity and the Strong Theory of Relative Identity
}

\author{
Daniel Molto 1
}

Published online: 3 July 2017

(C) The Author(s) 2017. This article is an open access publication

\begin{abstract}
In this paper, I consider the philosophical consequences of one tradition in Trinitarian theology, which emphasizes that each of the persons of the Trinity is wholly God. I pay special attention to Leftow's claim that the persons of the Godhead must be divine in the same sense of the word 'divine' as the Godhead itself. I argue that the existing philosophical account of the Trinity which best captures this view is what I have termed the 'Strong Theory of Relative Identity,' first proposed Peter Geach. I then develop what I take to be the most pressing objection to this account of the Trinity, namely that it cannot be supplemented with a coherent model-theoretic semantics. I end with a suggestion for responding to this objection.
\end{abstract}

Keywords Philosophical theology $\cdot$ Logic $\cdot$ Trinity $\cdot$ Identity

In recent philosophical theology, various accounts of the doctrine of the Trinity, the claim that the Christian God is triune (existing in three persons), have tried to steer a middle path between two heresies. On the one hand, orthodoxy is threatened by tritheism, the heretical view that there are three Gods, while on the other hand, avoiding tritheism runs the risk of falling into modalism, the heretical view that the individual persons of the Trinity are merely modes of the same entity. Social Trinitarianism tries to avoid modalism by stressing the distinctness of the divine persons. In so doing, it has faced accusations of tritheism. Latin Trinitarianism, by contrast, stresses the unity of God, at the expense of the distinctness of the persons and has traditionally

Daniel Molto

daniel.molto@york.ac.uk

1 University of York, York, YO10 5DD, UK 
been accused, by its detractors, of modalism. ${ }^{1}$ Social Trinitarianism has traditionally been much favored by the Eastern Church, while the most notable exponents of the Latin view have come from the Western Church (though by no means are all Western theologians defenders of Latin Trinitarianism). One of the historical reasons for the disagreement is the greater role accorded to the Athanasian Creed by the Western Church, and the corresponding emphasize placed by the latter on each of the persons of the Trinity being God 'whole and entire.' In recent years, perhaps the most important defender of the Latin tradition, and critic of Social Trinitarianism, has been Leftow (1999), who has argued that, among other problems with Social Trinitarianism, it risks collapsing into a form of Arianism, because it posits multiple ways in which something may be divine. However, as we shall see, constructing a Trinitarian account which avoids positing multiple ways of being divine is no easy feat. This paper will consider whether any of the Latin accounts of the Trinity can satisfy this proposed condition on orthodoxy.

In "The Logical Problem of the Trinity" section, I set out the logical problem of the Trinity. In "Social and Latin Trinitarianism" section, I outline the theological commitments that, according to one interpretation of the Latin tradition, rule Social Trinitarianism out as a model of the doctrine of the Trinity. In "Latin Trinitarianism: Current Accounts" section, I consider the major Latin accounts of the Trinity in the contemporary literature and argue that only a 'Strong' Theory of Relative Identity can satisfy the Latin theological disiderata identified in "Social and Latin Trinitarianism" section. Finally, in "Is the Strong Theory of Relative Identity Coherent?" section, I outline the cost of accepting such a theory by developing what I take to be the most serious objection to a Strong Theory of Relative Identity, that it is not compatible with classical semantics. I argue that it has not always been appreciated how deep this incompatibility goes, and I conclude that the Strong Theory of Relative Identity requires a non-classical semantics. The conclusion to be taken from these considerations is that a coherent account of the Trinity which avoids positing multiple ways of being divine does exist, but that the philosophical costs of adopting such an account are steep.

\section{The Logical Problem of the Trinity}

For the western Church at least, the definitive statement of the doctrine of the Trinity can be found in the Athanasian Creed. The Athanasian Creed involves 44 theological theses concerning the doctrines of the Trinity and the Incarnation. Among these theses are the following three:

(1) 'We worship God in Trinity and Trinity in Unity... Neither confounding the persons nor dividing the substance.'

\footnotetext{
${ }^{1}$ See McCall and Rea 2009: 1-15 and Moreland and Craig (2003) for good recent accounts of the difference between these two approaches.
} 
(2) 'So the Father is God, the Son is God, and the Holy Spirit is God.'

(3) 'And yet they are not three Gods, but one God.'

However, the conjunction of these three theses has the appearance of contradiction. Indeed, under quite plausible interpretations, a contradiction can be derived quite simply.

For example, if we treat 'God' as a count noun (a noun which can occur in the plural), formally to be written ' $G$,' 'person' also as a count noun, to be written as ' $P$,' 'is' as denoting the relation of identity, to be written ' $=$,' and the relation ' $x$ is the same $F$ as $y$,' to be written ' $={ }_{F}$,' as equivalent to ' $x$ is an $F$ and $y$ is an $F$ and $x=y$, for any count noun, $F$, then it seems plausible to take (1) to entail

(4) $P$ (the Father) $\wedge P$ (the Son $) \wedge P$ (the Holy Spirit) $\wedge$ the Father $\neq_{P}$ the Son $\wedge$ the Son $\neq_{P}$ the Holy Spirit $\wedge$ the Holy Spirit $\neq_{P}$ the Father,

to translate (2) as

(5) $G$ (The Father) $\wedge G$ (The Son) $\wedge G$ (The Holy Spirit),

and to take (3) to entail

(6) $\forall x \forall y G(x) \wedge G(y) \rightarrow x={ }_{G} y$.

If we also assume the following, initially plausible, rule of inference: ${ }^{2}$

$$
(S R I) \frac{x={ }_{F} y \wedge F^{1}(x)}{x={ }_{F^{1}} y}
$$

the, from these, the following deduction is possible:

Proof

1. $G$ (the Father)

2. $G$ (the Son)

3. The Father $=_{G}$ the Son

4. $P$ (The Father)

5. The Father $\neq_{P}$ the Son

6. The Father $=_{P}$ the Son
Omitting Conjunction on(5)

Omitting Conjunction on(5)

(1), (2), (6)

Omitting Conjunction on(4)

Omitting Conjunction on(4)

(SRI) on 3,4

$\perp 5,6$

Therefore, a very plausible interpretation of the Athenasian Creed, along with one plausible rule of inference for relativized identity relations (relations such as ${ }_{F}$ ) leads to contradiction. A series of strategies have been proposed to escape this consequence, to which I turn next.

\footnotetext{
${ }^{2}$ Strictly speaking ' $F$ ' and ' $F$ ', here schematically represent any sortals. Sortals are a subset of count nouns which convey a criterion of identity for the individuals falling under them. 'Woman' is a sortal, because there are a determinate number of women in the class, for example. 'Thing' is not a sortal, because it is not the case that there are a determinate number of things in the class.
} 
For what follows, to simplify matters and to avoid the ambiguity between the use of 'God' as a count noun and as a proper name, I will adopt the device (except when quoting) of replacing 'God' with 'the Godhead' when I intend to carry out singular reference, and 'divinity' when I intend to use a count noun.

\section{Social and Latin Trinitarianism}

One way to escape this problem is to adopt a form of Social Trinitarianism. As McCall and Rea explain the approach,

ST (Social Trinitarianism) is usually associated ... with the claims that it 'starts' with threeness and moves toward oneness, that the divine persons are numerically distinct, and that the unity of the Trinity can be understood by way of a 'social analogy': the divine persons are relevantly like a family, a supremely unified community of monarchs, or three human persons whose interpersonal relationships are so strong as to be unbreakable. McCall and Rea (2009: 2)

We can get a better handle on this by considering one influential version of Social Trinitarianism. Richard Swinburne sets out his views as follows:

On the account which I have given, the three divine individuals taken together would form a collective source of the being of all other things; the members would be totally mutually dependent and necessarily jointly behind each other's acts. This collective would be indivisible in its being for logical reasons-that is, the kind of being that it would be is such that each of its members is necessarily everlasting, and would not have existed unless it had brought about or been brought about by the others ... The claim that 'there is only one God' is to be read as the claim that the source of being of all other things has to it this kind of indivisible unity.

But then how is the claim that each of the individuals is 'God' to be understood? Simply as the claim that each is divine-omnipotent, perfectly good, etc. (Swinburne 1994: 27)

Swinburne's account involves the claim that the Godhead is 'a collective.' The persons are distinct entities, which, taken together, compose the divine collective. Other versions of Social Trinitarianism involve some other general term in place of 'collective.' For example, David Brown (1985, see also Leftow 1999: 217-221) sees the Godhead as something like a group mind, composed of three constituent minds. While Layman (1988) holds that the Godhead is the bearer of the sum of the properties of the three persons. So, while each of the persons of the Trinity are not omnipotent, the three persons taken together are omnipotent. All of these versions of Social Trinitarianism are structurally alike in the following respect. The Godhead is something over and above any one of the persons which constitute it, and the truth of statements of the form ' $x$ is divine' is grounded in $x$ 's possession of certain divine properties rather than any identification of $x$ with the Godhead. This means that, though the persons bear some salient relation to the Godhead, the persons are not themselves Godheads. This would mean that the relation '... is the same Godhead 
as...' is not an identity relation and therefore the crucial inference from $(3,4)$ to $(6)$ of the formal proof is blocked.

A long theological and philosophical tradition stands opposed to accounts such as these. Some of the objections target the coherence of Social Trinitarian accounts like Swinburne's. Others target the theological implications of the account, for example whether it can make sense of divine properties. However, the objection that I am interested in for this paper comes from Leftow (1999).

Leftow has argued that Social Trinitarian accounts depend for their coherence on an ambiguous use of the term 'divine,' such that the Godhead is divine in a different sense of the word than the sense in which each of the persons is divine. Leftow borrows a particular characterization of Arianism from Cornelius Plantinga (1989), ${ }^{3}$ according to which, Arianism is the view that one or more of the persons of the Trinity are divine only derivatively. Leftow argues that on the Social Trinitarian account

[t]here is but one Trinity. But if we take the Trinity's claim to be one God seriously, I argue, we wind up downgrading the Persons' deity and/or unorthodox. If we do not, 'the Trinity' is just a convenient way to refer to the three Persons, and talk of the Trinity makes no progress toward monotheism. We soon also find that the moves which most clearly show ST 〈Social Trinitarianism〉 to be monotheist repeatedly threaten to slide into Plantinga's sort of Arianism, the positing of more than one way to be divine.

Later, he returns to the charge of Arianism, saying

...even if Trinity monotheism avoids talk of degrees of deity, it faces a problem.

Either the Trinity is a fourth case of the divine nature, in addition to the Persons, or it is not. If it is, we have too many cases of deity for orthodoxy. If it is not, and yet is divine, there are two ways of being divine-by being a case of deity, and by being a Trinity of such cases.

Taken at face value, the claim that the Godhead and the persons must be divine in just the same sense of the word 'divine' suggests the following principle:

(Divinity): 'the Godhead is divine' must be true in virtue of the same kinds of facts as 'the Father (or the Son or the Holy Spirit) is divine.'

(Divinity) accords well with a particular strand of theological tradition that is taken by many in the west to be orthodoxy. This tradition emphasizes the oneness of the Godhead by committing to the further thesis that each of the persons of the Trinity is 'wholly God'. This is meant not simply in the sense of having no non-divine parts, but in the stronger sense of being all there is to the Godhead. This tradition may well have started as a reaction to Arianism, and can be traced to the council of Toledo in the seventh century, through the Athanasian creed, through the writings of various

\footnotetext{
${ }^{3}$ Having borrowed the characterization of Arianism from Plantinga, Leftow argues that Plantinga's own defence of Social Trinitarianism runs afoul of this kind of Arianism. Leftow disagrees, in passing, with Plantinga's claim that this kind of Arianism is rejected by the Nicene creed, but does still seem to think that this kind of Arianism is heretical (Leftow 1999: 221).
} 
Western Fathers and medieval Doctors of the Church, ${ }^{4}$ to the modern day. No clearer statement of this tradition can be found than that of the modern Catholic catechism:

The divine persons do not share the one divinity among themselves but each of them is God whole and entire: 'The Father is that which the Son is, the Son that which the Father is, the Father and the Son that which the Holy Spirit is, i.e. by nature one God.' (Catechism of the Catholic Church Part I, "Social and Latin Trinitarianism", Chapter 1)

If the Godhead is not shared out among the persons, but each of them is all there is to the Godhead, then the persons will indeed be divine in just the same way as the Godhead is divine. There will be nothing in virtue of which the Godhead is divine, which does not hold also for each of the persons. I will not try to motivate (Divinity), or defend the claim that it is a condition on orthodoxy. Rather I am interested whether there is a coherent interpretation of the doctrine of the Trinity that satisfies (Divinity) and what the philosophical costs of such a view might be.

This tradition clearly rules out Social Trinitarianism as characterized above. According to that view, as we saw, the persons constitute (or hold some similar relation to) the Godhead, and this is just what is being denied by the Latin tradition I am interested in here. I will next consider whether the major philosophical models of Latin Trinitarianism that can be found in the contemporary literature can go any further toward answering the logical problem.

\section{Latin Trinitarianism: Current Accounts}

We may classify contemporary Latin accounts into several groups. There are those theories, going back to Duns Scotus, which take the relation of the Godhead to the persons of the Trinity to be something like the relation between universals and their instances. ${ }^{5}$ There are accounts, following Abelard (Brower 2004, a similar view is defended more recently by Rea (2003)), according to which the relation that holds between the Godhead and the persons is a relation of numerical sameness but not one of genuine identity. Then there are the relative identity accounts, which hold that the Godhead is the same divinity as the Father, the Son, and the Holy Spirit, respectively (each of these is also the same divinity as each of the others); however, none of the persons is the same person as any of the others, or as the Godhead. According to a relative identity account of the Trinity, the relations '...is the same divinity as...' and

\footnotetext{
${ }^{4}$ For example, see Hilary of Poitiers

It seems impossible that one object should be both within and without another, or that ... these Beings can reciprocally contain One Another, so that One should permanently envelope, and also be permanently enveloped by, the Other, whom yet He envelopes. This is a problem which the wit of man will never solve, nor will human research ever find an analogy for this condition of Divine existence. But what man cannot understand, God can be.Concerning the Trinity 3:1
}

\footnotetext{
${ }^{5}$ The view defended by Jeffrey Brouwer and Michael Rea 2005 has a prima facie similarity to this view, though in a curious inverted form.
} 
'...is the same person as...' are not relations of classical identity (equivalence relations which guarantee the indiscernibility of their relata); nevertheless, they are relations of numerical identity (from ' $x$ is the same divinity as $y$,' we can infer 'there is one divinity'). Anscombe and Geach (1961) Martinich (1978, 1979), van Iwagen (1988, 2003), Cain (1989), and Conn (2012) have worked on this approach. The first we will consider, however, is Leftow's own account, which involves an analogy with time travel.

If time travel is possible, then it is apparently possible for one and the same person to be multiply instantiated simultaneously (in public time) in different spatial locations. For example, it is possible for a person, Leftow names her 'Jane,' to journey through time and join her earlier self. Presumably, if this is possible, it is possible for three instantiations of Jane to be present in the same room at one public time. Leftow suggests that this possibility serves as a model for the Trinity (2004). Each of the divine persons is like one of the instantiations of Jane; just as the three instantiations are all one and the same person, even though they do not have all the same properties (at least, they seem not to), so too, all three persons are one and the same divinity, and that single divinity is to be identified with a single divine substance persisting through time. It is easy to see why this account is generally considered a version of Latin Trinitarianism. The most apparent worry here is modalism rather than tritheism.

Leftow's account depends, then, on the coherence of time travel. There are, of course, well known objections to the metaphysical possibility of time travel, which I will not rehearse here. Assuming these can be answered, however, a theological worry remains. Leftow must explain what 'Jane' refers to here, the single substance or one of the instantiations? If the former, then it seems we have reached straightforward modalism. If the latter, and we take talk of 'three Janes' seriously, then how is this to be distinguished from accounts of Social Trinitarianism, whereby the persons are parts of the whole substance? ${ }^{6}$

Leftow emphasizes that he conceives the relation between the substance and each of the instantiations as being one of identity. He rejects that the instantiations are parts of Jane, not even temporal parts (Leftow is an endurantist). This is sufficient to distinguish his position from Social Trinitarianism, but it raises interesting questions about the kind of identity relation Leftow has in mind.

It seems to me that if the kind of time travel that Leftow needs to motivate his case is possible, then one of the following must be false.

(7) 'There are three divinities' if and only if 'There is some $x$, some $y$, and some $z$, where each is non-identical with the others and each is a divinity.'

or

(8) All relations of numerical identity are characterized by unrestricted Leibniz's Law, that is, that if $x$ and $y$ are identical, then $x$ and $y$ have all their properties in common.

\footnotetext{
${ }^{6}$ For a more developed formulation of related concerns, see Hasker (2009).
} 
It is easy to see why this is, if every Jane is identical to one common substance, then (assuming the Transitivity of Identity, which I do not imagine anyone wishes to reject) each is identical with each of the others. At the same time, the Janes do not have the same properties, for if they did then by parity of reasoning, so would the persons of the Trinity, and this really would be modalism. So either the Janes can be one in cardinality although they are non-identical, or they can be identical in spite of having different properties.

It seems, then, that Leftow has two options; reject (7) or reject (8). However, I think that, regardless of which of these Leftow adopts, his account will not satisfy (Divinity), the condition on successful Latin accounts of the Trinity which seemed implicit in Leftow's own attack on Social Trinitarianism.

If Leftow rejects (7), then he rejects a very plausible thesis concerning the relationship between identity and cardinality. Even then, though, this will not provide an account of the Trinity on which (Divinity) is satisfied. For on this account, the Godhead is divine in virtue of being identical with the Godhead, whereas the persons are divine in virtue of being counted as one, without being strictly identical. On this version of the account, then, there remain different ways of being divine.

Alternatively, one might reject (8). For example, one might restrict Leibniz's Law in the case of diachronic identity relations so that, rather than ranging over all properties, it ranges over only intrinsic properties. Perhaps Leftow can show that all the distinguishing properties of the individual persons are extrinsic and therefore no obstacle to identifying the persons as one (whether this turns out to be modalism is still a real worry, but not the one that interests me here). However, this attempt does no better with respect to satisfying (Divinity), because, again, a importantly different kind of relation obtains between the persons and the Godhead from that which obtains between the Godhead and the Godhead. In the former case, to avoid contradiction, it must be the case that the relation that holds between any one of the persons and the Godhead is non-Leibnizian, because they clearly do not have exactly the same properties. If it is an identity relation, it must be a diachronic relation where sameness of property is restricted to intrinsic properties, or something similar. The relation between the Godhead and the Godhead, by contrast is a relation of synchronic identity which does satisfy Leibniz's Law. It is by virtue of satisfying the latter, more fundamental relation, that the Godhead is divine, whereas it is by satisfying a weaker relation that the persons are divine.

Similar considerations, unsurprisingly, show that numerical sameness and instantiation accounts of the Latin Trinity also fail to satisfy (Divinity). The former are no different than the rejection of (7) above. These accounts posit a relation weaker than identity, and claim that it holds between each of the persons of the Trinity and the Godhead. These accounts do not, however, deny that genuine numerical identity exists. The Godhead, then, is still numerically identical with itself. Once again, it seems this account is committed to the Godhead being divine in virtue of satisfying a more fundamental relation to itself than the relation that grounds the claim that each of the persons is divine. Accounts like that of Duns Scotus, on which the relation that holds between the Godhead and the persons can be understood by analogy 
to the relation between a universal and its instantiations (or on the Brower and Rea (2005) view, according to which the relation is like the relation between a primary substance and a second substance), of course, also fail to satisfy (Divinity) for the same reasons. Theses accounts do not reject that the Godhead is genuinely numerically identical with the Godhead, and the relation that they claim holds between the persons and the Godhead is weaker than this identity relation. The Godhead's divinity is, then, grounded in a more fundamental relation than the person's divinity.

I take it to be a plausible thesis that the Godhead is divine simply in virtue of being identical with the, by hypothesis, one and only Godhead. If this is so, however, it is clear that no account of the Trinity can satisfy (Divinity) while assuming classical logic. The price of orthodoxy, if orthodoxy really does involve the satisfaction of (Divinity), is adopting a non-classical logic. There are several prima facie possibilities.

One possibility that has not been discussed at any length in the existing literature is to adopt a paraconsistent logic, accepting that the orthodox account of the Trinity is inconsistent, yet nevertheless true. However, paraconsistent logic, apart from its radical departure from classical logic, also accords ill with theological orthodoxy. The prospective benefit of adopting a paraconsistent logic, with respect to the doctrine of the Trinity, is that it allows the logical possibility of the various theological doctrines being simultaneously true, although they contradict one another. However, this sort of solution is very difficult to square with orthodoxy, statements of which are often framed in terms which seem to presuppose the law of non-contradiction. Take, for example the Athenasian Creed once again. It is not sufficient for orthodoxy that we hold that the inconsistent conjunction 'there is exactly one God and it is not the case that there is exactly one God, because there are three' be true. Consider the 18th line of the Creed,

[f]or like as we are compelled by the Christian verity; to acknowledge every

Person by himself to be God and Lord; So are we forbidden by the catholic religion; to say, There are three Gods, or three Lords.

Affirming the doctrines, then, is necessary but not sufficient for orthodoxy. Orthodoxy also involves not affirming the negations of the doctrines. This is just what would be involved in a solution depending on paraconsistency.

Apart from paraconsistency, the obvious alternative for blocking the deduction on page 2 is by rejecting the problematic rule of inference that I have called 'SRI.' This can be done by adopting a non-classical view of how relations like ' $={ }_{F}$ ' work. This is represented in the literature by the relative identity response to the logical problem of the Trinity, to which we turn next.

\section{The Relative Identity Solution}

The relative identity response was first proposed by Anscombe and Geach (1961) and Geach (1967). Geach attributes a theory of relative identity to Thomas Aquinas, and we can get a better grasp the significance of relative identity for Latin Trinitarianism, if we consider Geach's account of Aquinas. 
A few remarks on the logic of 'there is but one God' and 'the one and only God.' On Russell's theory of descriptions 'the one and only God is $X$ ' would be construed as meaning:

'For some $y, y$ is God, and for any $z$, if $z$ is God, $z$ is the same as $y$, and $y$ is $X$ '; And this, shorn of the final clause 'and $y$ is $X$,' would also give the analysis of 'there is but one God.' Aquinas would certainly have objected, on general grounds, to the clause ' $z$ is the same as $y$ '; the sameness, as we saw, must for him be specified by some general term signifying a form of nature. Now the general term that we need to supply here is clearly 'God'; so 'there is but one God' will come out as:

'For some $y, y$ is God, and, for any $z$, if $z$ is God, $z$ is the same God as $y$.' It is important to notice that this would leave open the possibility of there being several Divine Persons; there would still be but one God, if we could truly say that any Divine Person was the same God as any other Divine Person. Anscombe and Geach (1961: 118)

Therefore, on this view, all the $x$ s that are divine are also the same divinity as the Godhead, and together add up with the Godhead to a total of one divinity. The relation '... is the same divinity as...' is taken, by relative identity theorists, to be a genuine relation of numerical identity. This means that numerical identity relations can cross-cut, such that some $x$ and $y$ can be the same divinity and yet be different persons. On this view, this is simply how numerical identity relations work, and does not involve any incoherence. Some entity(ies) can be one when divided up according to one sortal-relative identity relation, while they can be three when divided up according to a different sortal-relative identity relation. If the relations '.. is the same divinity as...' and '... is the same person as...' were relations of classical identity (that is, relations characterized by Leibniz's Law, Symmetry, Transitivity, and, given the presence of sortals in these relations, Weak Reflexivity) this would be contradictory. ${ }^{7}$ So relative identity theorists reject that these sortal-relative relations of numerical identity satisfy Leibniz's Law.

It is important to note that this account comes in several importantly different forms. The distinction that matters for our present purposes is that between what I shall call 'strong' and 'weak' theories of relative identity. Weak theories of relative identity hold that there are absolute identity relations (characterized by Leibniz's Law) and relative identity relations (for which Leibniz's Law fails). Strong theories of relative identity hold that the only numerical identity relations that there are are non-Leibnizian relative identity relations.

Historically, Geach has been alone in committing himself to strong relative identity (1967). Other relative identity theorists have typically taken the rejection of

\footnotetext{
${ }^{7}$ Proof: Assume the Father is the same divinity as the Son, and that the Father is not the same person as the Son. By Leibniz's Law, all and only the properties of the Father are properties of the Son. The Father does not have the property of being the same person as the Son. But, by Reflexivity, the Son does have this property. This is a contradiction.
} 
absolute identity to be an unnecessary encumbrance to the theory which undermines its independent plausibility. ${ }^{8}$ Peter van Inwagen, in his influential 1988 paper 'And yet there are three Gods,' which reintroduced relative identity as an approach to the logical problem of the Trinity, declares himself neutral on the existence of absolute, non-relativized, identity (1988: 259). However, it is with respect to the satisfaction of (Divinity) that we can see why a relative identity theorist interested in providing a response to the logical problem of the Trinity might reject the existence of absolute identity altogether.

The weak relative identity theorist is in the same position as the defender of a 'sameness-without-identity' account of the Trinity, indeed they have a difficult time explaining how their account is any different. Once again, if it is allowed that there are genuine relations of absolute unrelativized identity, then it is overwhelmingly plausible (barring any particular reason for thinking otherwise) that the Godhead has this relation to itself. The Godhead, then, has this fundamental relation to itself, while the persons have the weaker, and one might certainly think derived, relation of sortalrelative identity '...is the same divinity as...' to the Godhead. This account fails to satisfy (Divinity) and certainly seems to be involving two different ways of being divine, one more fundamental than the other and attaching only to the Godhead.

The Strong Theory of Relative Identity, by contrast, will not, in fact cannot, say that the Godhead is absolutely identical with itself, for it holds that there is no such relation as '... is absolutely identical with...'. Rather, the strongest relation that the Godhead bears to itself is the relation '... is the same divinity as...'. It is in virtue of this relation, then, that the Godhead is divine. This is of course the same relation that each of the persons of the Trinity has to the Godhead as well. In addition, the three divine persons bears the relation '... is a different person from ...' to each of the other persons. This is why there are three persons, but one divinity. Note that on this account the threeness of the persons has no priority over the oneness of the divinity, the relative identity account of the Trinity involves two different relations of genuine identity (as opposed to equivalence) which cross-cut each other. On this account, the Trinity is not three different objects that have some common property that allows them to be counted as one in some derivative way. Rather it is a reality that does not in itself have a cardinality, but can be counted as one or three according to which of several equally legitimate identity relations is employed in the counting.

(Divinity) can only be satisfied by an account of the Trinity according to which the strongest relation that the Godhead holds to the Godhead is the same relation that each of the persons holds to the Godhead. This relation cannot be absolute identity if the resulting account of the Trinity is to be consistent, so it seems that the strongest relation that the Godhead can hold to the Godhead must be a relative identity relation or something very much like it. This speaks in favor of a strong relative identity account of the Trinity as the appropriate one for the particular theological view that I have been interested in in this paper.

\footnotetext{
${ }^{8}$ For example, Garbacz (2002), Griffin (1977).
} 


\section{Is the Strong Theory of Relative Identity Coherent?}

If the Strong Theory of Relative Identity offers the greatest promise for the kind of doctrine of the Trinity that is committed to (Divinity), then the incoherence of the former would cast grave doubts on the coherence of the latter. Moreover, many philosophers do think that the Strong Theory of Relative Identity is incoherent (Quine 1964, Alston-and-Bennett 1984; Dummett 1991; Hawthorne 2003; Le Poidevin 2009). These worries would be, at least partly, answered, if a Strong Theory of Relative Identity could be provided with a provably consistent first-order system and accompanying semantics. Several consistent logical systems compatible with the Strong Theory of Relative Identity have been developed. However, as we shall see, there are grave doubts about the possibility of providing a coherent semantics in particular. In this section, I will outline this objection, the most serious that the theory faces, and argue that it is even more serious than has hitherto been recognized. I will finish by proposing one avenue of escape from the objection.

Several attempts have been made to develop logical systems for theories of relative identity, notably, by Stevenson (1975), Griffin and Routley (1979); van Inwagen van Inwagen (1995) and Garbacz (2002). ${ }^{9}$ Not all of these, however, will serve our present purposes. The Stevenson logic, for example, is a logic of relative identity in name only. In Stevenson's logic, there are relations of identity that are relativized to general terms, but all such relations are Leibnizian. So statements of the form $\left\ulcorner a={ }_{F} b \wedge a \neq F_{F^{1}} b \wedge\left(F^{1}(a) \vee F^{1}(b)\right)\right\urcorner$ are contradictory (Stevenson 1975: 195). However, the relative identity solution to the logical problem of the Trinity turns on facts about the Trinity having just this form, specifically that, for example, the Father and the Son are the same divinity, but different persons. Pawel Garbacz's series of logics for relative identity go further than Stevenson's system, but also fall short of what is required on this picture. For the reflexivity of classical absolute identity is a feature of each of these systems, from which it follows that the Godhead is identical with the Godhead, but on pain of contradiction with none of the persons, as explained above. The logical systems in the literature which do model the Strong Theory of Relative Identity are the weakest of the Routley and Griffin systems, named by them 'Theory 1,' and the system sketched by van Inwagen.

van Inwagen's logic is a provably consistent system of natural deduction (van Inwagen 1988: 248-260), arrived at by adding just two new inference rules to the classical system of natural deduction for first-order logic (without identity). These are as follows:

Symmetry $_{R I}$

and

$$
\frac{x={ }_{F} y}{y={ }_{F} x}
$$

\footnotetext{
${ }^{9}$ To be sure, there are other alternative systems of first-order logic which may be compatible with strong relative identity; for example Wehmeier's Wittgensteinian-inspired 'logic without objectual identity' (Wehmeier 2012) and Krause and French's Schrödinger logics (Krause and French 2006, first developed by da Costa 1980). However, none of these is tailor-made for relative identity, and so I will not consider them further here.
} 
Transitivity $_{R I}$

$$
\frac{x={ }_{F} y, y={ }_{F} z}{x={ }_{F} z}
$$

These are, of course, relative identity versions of Symmetry and Transitivity. ${ }^{10}$ However, van Inwagen does not provide a relative identity version of Reflexivity and provides nothing similar to Leibniz's Law.

As the Quinean principle 'no entity without identity' retains its plausibility even if the Geachean view of identity is true, some version of Reflexivity is desirable. Such a rule can be supplied from the Routley and Griffin system (Griffin-and-Routley 1979: 76-77)):

Reflexivity $_{R I}$

$$
\frac{F(x)}{x={ }_{F} x}
$$

On the other hand, the absence of any principle of substitutivity in a first-order logic for strong relative identity is unavoidable, so no inference of the form

$$
\frac{x={ }_{F} y, F^{1}(x)}{F^{2}(y)}
$$

are valid in a first-order logic for strong relative identity. We need not, however, follow van Inwagen in concluding that all such inferences are substantive metaphysical theses and not guaranteed by logic (van Inwagen 1988: 256), because second-order systems have the resources to provide principles of substitutivity that are consistent with strong relative identity. ${ }^{11}$ There are, therefore, formal systems compatible with strong relative identity.

A curiosity of van Inwagen logic is that all reference is carried out by quantified expressions (van Inwagen 1988: 260), because van Inwagen believes singular reference is incompatible with relative identity. The supposed incompatibility of strong relative identity with singular reference is, in fact, frequently pointed out by its detractors (Alston and Bennett 1984, Hawthorne 2003). van Inwagen puts the point this way:

The philosopher who eschews classical, absolute identity must also eschew singular terms, for the idea of a singular term is... at least in currently orthodox semantic theory, bound to the classical semantical notion of reference or denotation; and this notion, in its turn, is inseparably bound to the idea of classical identity. It is a part of the orthodox semantical concept of reference that reference is a many-one relation. And it is a part of the idea of a many-one relation-or a one-one relation, for that matter-that if $x$ bears such a relation to $y$ and bears it to $z$, then $y$ and $z$ are absolutely identical. (That is what it says on the label.) (van Inwagen 1988: 259)

\footnotetext{
${ }^{10}$ In fact, in van Inwagen's paper, they appear using the schematic letter ' $I$ ' in place of the symbol ' $={ }_{F}$ ', however the latter term, by involving a schematic term for sortals will allow us to add a version of reflexivity as well, which would be impossible using the simple schematic letter ' $I$.'

${ }^{11}$ An example can be found in Griffin and Routley's 1979 second-order system for relative identity, in which they are able to define the notion of predicate 'domination.' That system includes an absolute identity relation, but this is not required for the definition of property domination.
} 
van Inwagen's point, then, is that the classical semantics for singular terms depends on the relation between terms and denotations being many-one, and that depends on absolute identity, in that, for a relation to be many-one, it must be the case that there is one relata that is distinguished absolutely. And indeed, classical semantics stipulates that the interpretation of any name in a language is an element in the domain of discourse. Thus,

If $N$ is the set of all names in a language, $L$, and $S$ is a structure $\langle D, I\rangle$, then, for every element $n \in N, I(n) \in D$.

van Inwagen thinks he escapes the problem, by ramsifying the terms 'Father,' 'Son,' so that all occurrences of these are replaced by the quantified expressions ' $x$ such that $x$ begets' and ' $x$ such that $x$ is begotten' (van Inwagen 2003: 72-73). He shows how we can state the orthodox account of the Trinity in this way. However, eschewing singular terms, as van Inwagen does, will not on its own solve the problem, because the issue generalizes, or so it seems. If classical semantics is committed to the existence of absolute identity relations in order to distinguish the referents of names, then it would appear that it is equally committed to absolute identity relations in order to distinguish the assignments of variables. This problem was, in fact, the first objection raised against theories of relative identity by Quine in his review of Geach's Reference and Generality.

Quine says,

[t]his doctrine [Geach's denial of the existence of an absolute relation of identity] is antithetical to the very notion of quantification, the mainspring of modern logic. Quantification depends upon there being values of variables, same or different absolutely; grant quantification and there remains no choice about identity, not for variables. For a language with quantification in it there is but one legitimate version of " $x=y$ ". (Quine 1964: 101)

This point is expanded upon by Dummett,

If we are engaged in giving a verbal statement of the interpretation of the object-language, we have first to specify the domain of the variables. To give the interpretation of the non-logical constants, we have to be able to refer in the metalanguage to elements of that domain, or to pick out subsets of it. In order to know whether a given interpretation is admissible, that is, intelligible, we must know when two terms of the metalanguage pick out the same element of the domain, since the requirement that one and the same element, considered as picked out by each of two distinct singular terms of the metalanguage, should behave differently in respect of the satisfaction of some predicate of the object-language will render the interpretation contradictory and so inadmissible. Hence, to give an interpretation relative to a domain presupposes a relation of identity defined over it. And, according to the present argument, the same applies to the case in which we have only a mental apprehension, rather than a verbal statement, of the interpretation. Dummett (1991: 294)

It is odd that many of the more recent discussions of relative identity have focused on its incompatibility with the classical semantics for proper names. This problem 
can be avoided by eschewing names, but a system that cannot be provided with a semantics for proper names or bound variables is clearly not going to be capable of doing the work required of it. In fact the problem goes deeper even than this, as the Strong Theory of Relative Identity is incompatible with the classical semantics for predicates as well, because the latter entails that if $F_{n(n \geq 1)}$ is the set of all $n$-place predicates in $L$, then $S$ must be such that for every $F \in F_{n}, I(F)$ is a set of $n$-tuples such that every element of every $n$-tuple in $I(F)$ is an element in $D$.

What lies at the bottom of these incompatibilities, is that it is implicit in classical model-theoretic semantics that there exists a collection of discrete entities, which we have called $D$, which are the possible denotata of the singular terms, the possible assignments of the variables and the elements of the $n$-tuples which are taken as the referents of relations. Moreover, it is the standard assumption that $D$ is a ZF set. The traditional interpretation of the formal language of set theory (both Naive and ZF) is incompatible with the Strong Theory of Relative Identity because the traditional interpretation presupposes that any set contains a number of elements distinguished from one another absolutely.

As Cantor puts it, 'a set is a collection into a whole of definite, distinct elements of our intuition or of our thought' (as quoted in Fraenkel 1966: 9). And again,

[A] variety (an aggregate, a set) of elements that belong to a certain conceptual subject is well defined if by virtue of its definition and of the Principle of Excluded Middle it must be determined as internally determined whether an element of such a conceptual subject is an element of the variety, so as if two objects belonging to the set, despite the formal diversity by means of which they are given, are identical or not. (As quoted in Krause and French 2006: 259-269.)

It is clear, from this, that some rather radical departure from conventional modeltheoretic semantics is required for this project. Perhaps, following Leśniewski, the need for a semantics will be denied, or, less radically, the need for a semantics which assigns values to specific components of propositions. In other words, a Strong Theory of Relative Identity might involve rejecting the principle of compositionality.

There is, of course, support in the contemporary literature for abandoning the compositionality principle. However, the arguments that are usually introduced in order undermine the principle will not be of much support for the current project, since these arguments aim to show that something further is needed for a complete semantics beyond interpretations of terms. The current proposal is that we can have a sufficient understanding of the meanings of propositions without being able, even in theory, to specify non-linguistic items to which the sub-propositional components of language stand in relations of denotation.

This radical proposal is not obviously incoherent, but the cost seems to be very great indeed, and not one to be accepted lightly. It would be worthwhile, then, to search for a less radical alternative. If the compositionality principle is true, then the coherence of strong relative identity depends on the possibility of a semantic account of the sub-propositional parts of a language which does not require that the values of the linguistic items be dinstinguishable in any absolute way, and therefore allows for an absolute identity relation to be defined over the domain. 
We have seen that this is ruled out in conventional model-theoretic semantics by the very nature of sets. The remaining alternative, then, is to look beyond traditional ZF set theory. Garbacz (2002: 28) in the course of developing a series of logics for what I have termed weak theories of relative identity, notes in passing that, for a nonclassical framework for a corresponding semantics, one might turn to non-classical set theories such as Blizzard's Multi-Set Theory (1989) or Krause's Quasi-Set Theory. Garbacz believes, however, that the prospects are not promising, though he does not elaborate on why he thinks so.

It is fairly apparent on reflection that the theory of multi-sets will not be helpful in this regard. The special characteristic of the theory of multi-sets is that multi-sets may contain the same elements several times over. In other words, whereas $(x, y, y)$ is just the same ZF set as $(x, y)$, they are different multi-sets because distinguished by the double occurrence of the element $y$ in one but not the other. Multi-set theory does not abandon the use of absolute identity in distinguishing elements from one another, indeed it seems to require it for the very definition of a multi-set. The upshot is that if a term maps onto a single determinate value, either an element or a multi-set of iterations of given elements, then the denotation of the term will bear an absolute identity relation to itself. Once again, on this account, the Godhead cannot but be identical with the Godhead, and non-identical with the persons.

However, I do think that Garbacz's judgment in the case of Quasi-Set Theory is too quick. I think that this theory shows that the strong relative identity theorist could reject ZF Set Theory as the groundwork theory for a semantics in favor of a nonclassical set theory which allows for elements without identity conditions. QuasiSet Theory is a provably consistent non-classical set theory originally developed in Krause's paper 'On a Quasi-Set Theory' (Krause 1992) and subsequently, in more detail, by Krause and French $(2006,2010)$. The theory of quasi-sets involves sets with elements of two different kinds: one labeled ' $M$-atoms,' objects for which all the traditional laws of logic (including identity) apply. These are no different from the Ur-elements of ZFU Set Theory. The other entities are called ' $m$-atoms.' As Krause explains,

[t]he atoms of the other kind ( $m$-atoms) may be intuitively thought of as elementary particles of modern physics, and we will suppose, following Schrödinger's ideas, that identity is meaningless with respect to them (Schrödinger 1952: 16-68). Then we will admit that the Traditional Theory of identity (TTI) does not apply to the $m$-atoms. These facts enable us to hold, with regard to the $m$-atoms, that the concepts of indistinguishability and identity may not be equivalent. Therefore, roughly speaking we can say that a q-set (quasi-set) is a collection of objects (called elements) such that to the elements of one of the species (the $m$-atoms), the notion of identity (ascribed by classical logic and mathematics) lacks sense. (Krause 1992: 402-403)

Therefore, for any $m$-atom, $x$, it is not the case that $x$ is absolutely identical with $x$. This means that a quasi-set of $m$-atoms cannot be thought of as composed of ultimately-fine-grained elements distinguished from one another absolutely. Yet, we can quantify over such items, and make predications of cardinality about q-sets of $m$-atoms (at least, Krause and French introduce a 'quasi-cardinality' into their 
language which allows them to make such predications). What is the significance of this for the relative identity solution to the logical problem of the Trinity? The problem that we had identified was that, on any semantic account which designates a value for the term 'the Godhead' which bears an absolute identity relation to itself and is distinguished from other possible values by negated relations of absolute identity, then, given that in any orthodox theory of the Trinity there are statements of the form ' $P$ (the Godhead) $\wedge \neg P$ (the Father),' on pain of contradiction, the Godhead will bear at best a weaker-than-absolute relation of identity to the Father, while simultaneously bearing the more fundamental absolute identity relation to itself. Such a theory would fail to satisfy (Divinity). The Godhead would be divine in virtue of just being the very thing it is, the Persons of the Trinity would be divine in virtue of holding weaker equivalence relations (call them a kind of identity if you want) to the Godhead. The escape offered by a Geachean account is to deny that even the Godhead bears the privileged absolute identity relation to itself. The question facing this account is whether it does not simply collapse into the orthodox theory of identity when the time comes to specify the semantic values of terms. The existence of provably consistent theories of sets which do not presuppose the absolute identity or non-identity of their elements shows us that, contra Quine and Dummett, neither the mere specification of a domain nor quantifying over a domain is on its own is sufficient to guarantee that the elements of the sets or the possible assignments of the variables are distinguished from one another absolutely. If there can be sets of $m$ atoms and if we can quantify over these items, then it is not the case that everything our language is equipped to talk about needs to be (absolutely) self-identical. This, I think, answers what I take to be the major objection to the coherence of relative identity. $^{12}$

I conclude then, that at the cost of adopting the Strong Theory of Relative Identity, a solution to the logical problem of the Trinity can be found which avoids the consequence that the Godhead and the persons of the Trinity are divine in different ways.

\section{Conclusion}

The upshot of the discussion in 'Latin Trinitarianism: Current Accounts' section is that the only account of the Trinity in the literature which can preserve orthodoxy and satisfy (Divinity) involves adopting a logic of strong relative identity. That is, a logic in which absolute, universally reflexive, identity does not occur as a primitive and cannot be introduced by definition.

The costs of such a strategy are high. As well as giving up the relation of identity, and in particular giving up Leibniz's Law, it is also necessary to give up on any

\footnotetext{
${ }^{12}$ The position being argued for in this section is not that the persons of the Trinity are to be thought of as similar to quantum particles, for which q-set theory was designed. I do not entertain the hope of shedding very much light on the metaphysics of the Trinity by making an analogy with quantum phenomena. The point is simply that, with the development of the formal apparatus to deal with sets of non-individuals, we have reason to think that the notions are quantification and a domain of discourse are not inherently tied to absolute identity.
} 
semantic account which attaches absolutely individuated values to terms. This means giving up the possibility of genuine singular reference. ${ }^{13}$ However, I have argued that this does not show that the emerging picture is incoherent, because quantification does not necessarily depend on the assignment of determinate values for variables. I conclude that the account can escape the most serious objection that is raised against it.

Open Access This article is distributed under the terms of the Creative Commons Attribution 4.0 International License (http://creativecommons.org/licenses/by/4.0/), which permits unrestricted use, distribution, and reproduction in any medium, provided you give appropriate credit to the original author(s) and the source, provide a link to the Creative Commons license, and indicate if changes were made.

\section{References}

Alston, W., \& Bennett, J. (1984). Identity and cardinality: Geach and Frege. The Philosophical Review, $93,553-567$.

Anscombe, G.E.M., \& Geach, P.T. (1961). Three philosophers: Aristotle; Aquinas; Frege. Ithaca: Cornell Press.

Brower, J.E., \& Rea, M. (2005). Material constitution and the trinity. Faith and Philosophy, 22(1), 57-76.

Cain, J. (1989). The doctrine of the trinity and the logic of relative identity. Religious Studies, 25(2), 141152.

Conn, C.H. (2012). Relative identity, singular reference, and the incarnation: a response to Le Poidevin. Religious Studies, 48, 61-82.

da Costa, N. (1980). Ensaio Sobre os Fundamentos da Logica. São Paolo: Universidade de São Paolo.

Dummett, M. (1991). Does quantification involve Identity?'. In Lewis, H.A., \& Geach, P. (Eds.) Philosophical encounters. Dordrecht: Kluwer Academic Publishers.

French, S., \& Krause, D. (2006). Identity in physics: a historical, philosophical and formal analysis. Oxford: Oxford University Press.

French, S., \& Krause, D. (2010). Remarks on the theory of quasi-sets. Studia Logica, 95(1/2), 101-124.

Garbacz, P. (2002). Logics of relative identity. Notre Dame Journal of Formal Logic, 43, 27-50.

Geach, P.T. (1967). Identity. Review of Metaphysics, 21, 2-12.

Griffin, N. (1977). Relative identity. Oxford: Clarendon Press.

Griffin, N., \& Routley, R. (1979). Towards a logic of relative identity. Logique Et Analyse, 22, 65.

Hasker, W. (2009). A Leftovian trinity?. Faith and Philosophy, 26, 154-166.

Hawthorne, J. (2003). Identity. In Loux, M., \& Zimmerman, D. (Eds.) The Oxford handbook of metaphysics (pp. 99-130). Oxford: Oxford University Press.

Krause, D. (1992). On a quasi-set theory. Notre Dame Journal of Formal Logic, 33(3), 402-11.

Layman, C.S. (1988). Tritheism and the trinity. Faith and Philosophy, 5(3), 291-298.

Le Poidevin, R. (2009). Identity and the composite Christ: an incarnational dilemma. Religious Studies, 45, 167-186.

Leftow, B. (1999). Anti Social trinitarianism. In The trinity. Oxford: Oxford University Press (pp. 203249).

McCall, T., \& Rea, M. (Eds.) (2009). Philosophical and theological essays on the trinity. Oxford: Oxford University Press.

Martinich, A.P. (1978). Identity and trinity. Journal of Religion, 58, 169-181.

Martinich, A.P. (1979). God, emperor and relative identity. Franciscan Studies, 39(1), 180-191.

\footnotetext{
${ }^{13}$ In Quasi-set theory, it is impossible to single out, or name, $m$-atoms (Krause and French 2006: 320), and endorsing what Michael Dummett describes as an 'amorphous lunp' picture of the fundamental ontology of the universe. This suggests that van Inwagen's strategy of treating the apparent singular terms of the doctrine of the Trinity as quantified expressions is unavoidable on the relative identity account. However, there is some theological motivation from the literature on Apophaticism.
} 
Moreland, J.P., \& Craig, W.L. (2003). Philosophical Foundations for a Christian Worldview. InterVarsity Press.

Rea, M. (2003). Relative Identity and the doctrine of the trinity. Philosophia Christi, 5(2), 431-445.

Schrödinger, E. (1952). Science and humanism; physics in our time. Cambridge: Cambridge University Press.

Swinburne, R. (1994). The Christian God. Oxford: Clarendon Press.

Stevenson, L. (1975). A formal theory of sortal quantification. Notre Dame Journal of Formal Logic, 16(2), 185-207.

van Inwagen, P. (1988). And yet there are not three Gods, but one God. In Morris, T. (Ed.) Philosophy and the Christian faith (pp. 241-278). Notre Dame: University of Notre Dame Press.

van Inwagen, P. (2003). Three persons in one being: on attempts to show that the doctrine of the trinity is self-contradictory. In Stewart, M.Y. (Ed.) The trinity: east/west dialogue (pp. 83-97). Boston: Kluwer.

van Inwagen, P. (1995). God, Knowledge \& Mystery: Essays in Philosophical Theology. Ithaca, NY: Cornell University Press.

Quine, W.V.O. (1964). Review of reference and generality. The Philosophical Review, 73, 100-104. 